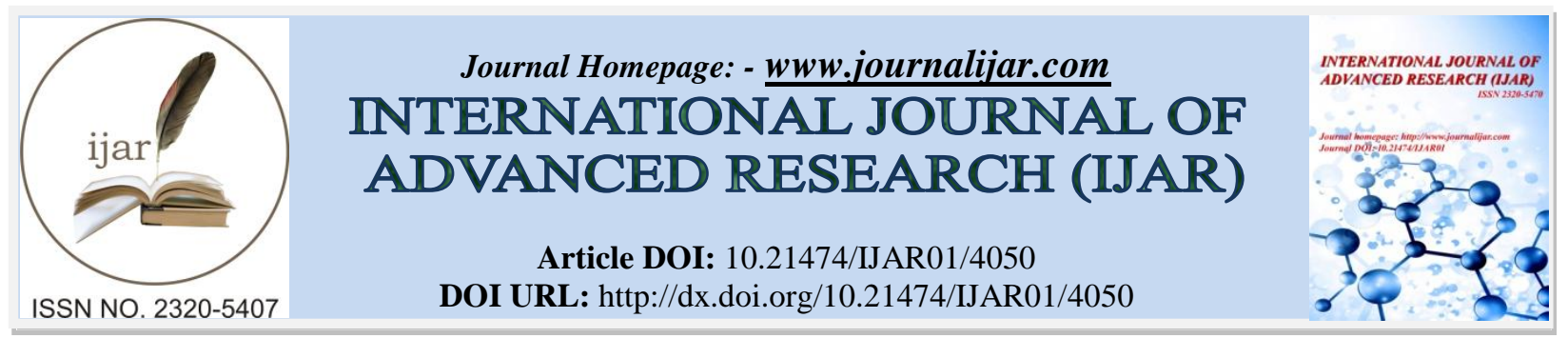

RESEARCH ARTICLE

\title{
EFFICACY OF DIFFERENT ESSENTIAL OILS, USES IN CASE OF TREATMENT AND CONTROL THE HEAD LICE.
}

S H. Salehi and G. Heshmat.

Department of pharmacy, University of Canberra, Canberra, Australia.

\section{Manuscript Info}

Manuscript History

Received: 16 February 2017

Final Accepted: 21 March 2017

Published: April 2017

\begin{abstract}
The head lice (Pediculus capitis) which cause pediculosis is an important infectious agent all around the world and in the history of mankind pediculus capitis is one of the oldest known parasites. Head lice settled in the head scalp especially in the occipital and temporal region and cause infestation by sucking blood. Head lice often seen in almost in every region of the world especially in the cold and temporal climate and reports shows that it can be seen frequently in the winter months.

Geographic region inhabited by society, climate condition ethnic various depending on the properties and hygiene, however it can be seen in each type of socioeconomic environment. Because of the good movement of the head lice, bad hygiene condition such as prison, camps, schools, kindergartens, public shelters, and also during war, flood or natural disaster such as earthquake can be seen more frequently. Studies illustrate that head lice is very common between female student, their long hair and close relationship shows as a cause of frequent occurrence.

In this case, pruritus of variable intensity and allergic reactions may occurs by head lice saliva and faecal also other secondary contamination have been occur associated to scratching ,abrasion and crusting such as lymphadenopathy infections. The conventional head lice products shows low efficacy because of emerging resistance and cross-resistance by head lice. Thereby growing tendency to use nontoxic and natural anti-lice product with low chance of evaluation of resistance promote scientist to search new control products from, plant extract and plant derived compounds especially essential oils.
\end{abstract}

Copy Right, IJAR, 2017,. All rights reserved.

\section{Introduction:-}

Head lice infestation is caused by pediculus humanus capitis De Geer, blonging to the family Pediculocidae, wingless and strictly obligatory ectoparasite. Head lice are highly propagate only on human scalp and hair and transmission occurs by direct head-to-head contact. Head lice may lead to enormous pruritus, skin inflammation, urticarial, exudation, excoriation, conjunctivitis, lymph node swellings, eczema, scars, hair glue-up to "plica polonica" ending in pain and restless especially in children. The optimal method for the diagnosis of active head lice infestation is dry/wet combing by using most common pediculicide such as, organochlorine( DDT and Lindane), organophosphorus (malathion), carbamet (carbaryl), pyrethrin (permethrin and $\delta$-phenothrin), and avermestin 
(ivermectin-orginated from Streptomyces avermitilis) insecticide(Yang et al. 2004). Unfortunately in recent years head lice shows a high resistance to existing products (Abdel-Ghaffar et al. 2009; Di Campli et al.2012; Feldmeier 2012).

Dichlorodiphenyltrichloroethane (DDT) was discovered in 1939 and used to control head lice until the end of World War 2. Developing resistance to DDT encourage scientist to find new insecticide. Late of 1940 Lindane, an organochlorine, was founded to be more effective than DDT and gradually replaced in many countries. Currently in many countries the mainstay of head lice treatment are topical chemical insecticide. Finally scientist start to investigate alternative treatments because of tree main reason, first one is to deal with created resistance, secondly is safety reason (some products are flammable or even if they are not flammable without contact to hair, may become inflamed when there is a mixture consisting of hair and hair-lice compound, some products are contain component such as do silicon-derivates with their volatile oil that may harmful for the surface of lung epithelia or component may induce harm if they are transported by a carrier in to the skin) and finally because of prohibitive cost of synthetic pyrethrins and pyrethroids (Heukelbach et al 2006, p. 279; Abdel-Ghaffar et al.2009).

\title{
Mechanism of action:-
}

There are many diverse category of products formulated for treating head louse infestation and many different sorts of active constituents. Numerous groups of insecticides that works in contradiction of the insect nervous system by either blocking nerve impulses or by over stimulating them. A nerve impulse be made up of electrical charge that transferrable along the nerve path. This electrical charge is created by a complex process in which the nerve cell pumps ions in and out through the membrane that surrounds the cell. The nerve ends do not touch but have synapses between them. The electrical impulse is not able to cross this gap. Most nerve impulses are able to cross the junction between nerve cells using what is known as a transmitter-substance as a connection. The transmitter substance is concealed from the end of the nerve cell when it is stimulated by a nerve impulse. One of the most common transmitter-substance is acetylcholine. When the nerve impulse reaches the junction acetylcholine is a connection, so the impulse can pass over and after the impulse is passed on the acetylcholine is broken down by an enzyme called acetylcholinesterase (Waghmars and Dhumal 2014). Natural product modes of action are not expected to be different.

\author{
Summary of species with documented activity against Pediculusis humanus capitis:- \\ Myrtaceae Melaleuca alternifoliaHeukelbach et al. (2006) \\ Meliaceae Azadirachta indicaHeukelbach et al. (2006) \\ Rutaceae Citrus paradise Abdel-Ghaffar et al. (2009) \\ Laminaceae Lavandula angostifolia \\ Myrtaceae Eucalyptus globulusToloza et al. (2009) \\ Annonaceae Annona squamosalHeukelbach et al. (2006) \\ Lamiaceae Mentha piperita Alankar (2009) \\ Thymus vulgaris Veal (1996) \\ Rosmarinus officinalis Veal (1996) \\ Arecaceae Cocos nucifera Lin\& Wilkens (2006) \\ FabaceaeAbrus precatoriousUpadhyay et al. (2011) \\ MyristicaceaeMyristica fragrans Veal (1996) \\ Lauraceae Cinnamonum zeylanicum Veal (1996)
}

\section{Natural product insecticides:-}

Tea tree oil

Tea tree oil is distilled by steam from the leaves of the tea tree, Melaleuca alternifolia and is a complex mixture of over 100 hydrocarbons and terpenes (Heukelbach et al. 2006). Veal (1996) found 94\% mortality against body lice with $1 \%$ emulsion of tea tree oil in water, furthermore a mixture of tea tree oil with cinnamon leaf oil (1:1) at $1 \%$ with $40 \%$ ethanol showed $100 \%$ efficacy against adult body lice after a $17 \mathrm{hr}$ exposure. In another study tea tree oil illustrates less efficacy than $\delta$-phenothrin and pyrethrum. Moreover in vitro study against head lice showed that $1 \%$ tea tree oil caused no mortality after 2 hours while $10 \%$ concentration demonstrates $86 \%$ mortality (Heukelbach et al. 2006). Heukelbach find $97 \%$ mortality of head lice after four hours with an emulsion of $5 \%$ tea tree oil in $20 \%$ ethanol. The most effective components which are $100 \%$ effective against head lice at $10 \%$ concentration can be mentioned as terpinene-4-ol, terralin, and $\alpha$-terpeninol (Walton et al. 2004). Tea tree oil shows 94.1\% on adult and 
$59.1 \%$ on eggs mortality by using water as a solvent, while solvent changes with ethanol mortality percentage is $93.2 \%$ on adult and $83.3 \%$ on eggs head lice.

\section{Neem extract:-}

About 150 compounds have been isolated from neem tree. Neem tree extract (Azadirachta indica) killed head lice slowly in vitro in a filter paper test and was less effective than Malathion, permethrin and benzyl benzoate (Heukelbach et al. 2006). Another study explain the effectiveness of neem seed- based shampoo product formulation kills mechanically significantly eggs, juveniles and adult body and head lice and thus offers a complete treatment from head lice infestations upon a single application of the shampoo. The shampoo enters the aeropyles of the eggs and cover their surface whilst in motile stage the shampoo penetrates the lateral tracheal openings, also this shampoo tested dermatologically and results shows that this product is very safe and skin-friendly (pittermann et al. 2008), thus it makes this product possible to get rid of head lice upon a single application. The shampoo enters the aeropyles of the eggs and cover their surface whilst in motile stage the shampoo penetrates the lateral tracheal openings (Mehlhorn et al. 2011).

\section{Grapefruit extract:-}

Licatack® is a newly developed anti louse shampoo that contains extracts of grapefruits and high value shampoo components. This product had been tested, and demonstrate very good skin safety and other dermatological aspects. The clinical test result demonstrates full activity of this product in the case of a very high infestation proportion (Abdel-Ghaffar et al. 2009).

\section{Custard apple seed extract:-}

Custard apple has been used in traditional Thai medicine against pediculosis since lone ago. A formulation containing 20\% Annona squamosal seed extract plus petroleum ether was illustrated high efficacy against head lice infestation in a small controlled trial (93\% mortality of head lice). Moreover this product showed more than $90 \%$ efficacy against head lice in three hours after application, as compared with $25 \%$ benzyl benzoate which killed $60 \%$ of lice in the control group Custard apple seed extract in coconut oil killed $98 \%$ of head lice within two hours (Heukelbach et al. 2006).

\section{Abrus precatorius:-}

Is a woody plant distributed broadlyentirely overIndia and the plant is conventionally used for the cure of sore tongue and it also has diaphoretic action. Seeds of Abrus precatorius are frequently used as purgative, emetic, aphrodisiac and in nervous disorder in traditional and popular medicines. A. precatorius seeds are known for their toxicity but petroleum ether extract do not contain toxic principle. The use of A.precatorius extract for controlling lice infestations has been valid from the excellent results got after screening for potential anti-lice and ovicidal activity.Effects of $A$. precatorius seed extracts against Pediculus humanus capitis adults and nymphs demonstrates that in $15 \%$ concentration seed oil in petroleum ether is able to kill $100 \%$ of head lice and A. precatorius appear as a good alternative instead of chemicals for treating human head lice (Upadhyay et al 2011)

\section{Thymus vulgaris plus Rosmarinus officinalis:-}

Veal (1996) state, Red thyme, using water as a solvent followed by a rinse illustrates $100 \%$ mortality on adult headlice and $50.8 \%$ on eggs, while solvent changes by ethanol, mortality percentage shows difference by $83.9 \%$ on adult, $92 \%$ on eggs on head lice. On the other hand rosemary oil demonstrates $79.5 \%$ mortality using ethanol as a solvent on adult head lice.A mixture of $4 \mathrm{ml}$ of Red thyme and $6 \mathrm{ml}$ of Rosemary oil using $40 \%$ ethanol as a solvent tested and results shows, $87.3 \%$ by using rinse and $87 \%$ without using rinse in 17 hours exposure period.

\section{Mentha piperita, Myristica fragrans\& Globolus eucalyptus:-}

One essential oil based item for consumption containing $11.0 \%$ eucalyptus oil was stated to have an efficacy of $82.5 \%$ against head lice compared to kill rate of 36.15 for a product containing pyrethrins and piperonyl butoxide (Barker and Altman 2010). In the case of lotion in ethanol 96\%, the once containing peppermint, eucalyptus and lavender, did not show a significant activity while the mixture of peppermint and eucalyptus in a totalconcentration of $10 \%$ showed the best performance. The study also demonstrate that addition of aliphatic alcohols enhance the insecticidal efficacy, and insecticidal activity systematically increase with increase in carbon atoms in the aliphatic alcohols and maximum activity was observed when the total number of carbon atoms was 12 (Gonzalez Audino et al. 2007).The study use the mixture of $3 \mathrm{ml}$ Peppermint oil and $7 \mathrm{ml}$ Nutmeg oil using $40 \%$ ethanol as a solvent and results shows $100 \%$ mortality in both using rinse and without rinse in 17 hours exposure period Veal (1996). 


\section{Cinnamonum zeylanicum \& Mentha piperita:-}

Study represented percentage of mortality $86 \%$ adult and $25.7 \%$ eggs of head lice of cinnamon leaf, using water as solvent. On the other hand researchers change the solvent and using ethanol followed by rinse and the results illustrate $100 \%$ mortality in both adult and eggs. The mixture of tea tree oil and cinnamon leaf in the same proportion of $5 \mathrm{ml}$ of each in $40 \%$ ethanol as a solvent shows $100 \%$ mortality by using rinse and without risen in 17 hours exposure(Veal 1996).

\section{Reference:-}

1. Abdel-Ghaffar, F, Semmler, M, Al-rasheid, K, Klimpel, S \& Mehlhorn H 2009, 'Efficacy of a grapefruit extract on head lice: a clinical trial', Parasitology Resarch, vol. 106, no. 2, pp. 445-449.

2. Alankar, S 2009, 'A review on peppermint oil', Asian journal of pharmaceutical and clinicall research, vol. 2, no. 2, pp. 27-33.

3. Barker, SC \& Altman, PM 2010, 'A randomised, assessor blind, parallel group comparative efficacy trial of three products for the treatment of headlice in children - melaleuca oil and lavender oil, pyrethrins and piperonul butoxide, and a "suffocation" product', BMC Dermatology, vol. 10, no. 6, pp. 1-8.

4. Di Campli, E, Di Bartolomeo, S, Delli Pizzi, P, Di Giulio, M, Grande, R, Nostro, A \& Cellini, L 2012, 'Activity of tea tree oil and nerolidol alone or in combination against Pediculus capitis (head lice) and its eggs', Parasitology Research, vol. 111, no. 5, pp. 1985-1992.

5. Feldmeier, H 2012, 'Pediculosis capitice: new insight into epidemiology, diagnosis and treatment', European Journal of Clinical Microbiology\& Infectious Diseases, Vol. 31, no. 9, pp 2105-2110.

6. Gonzalez Audino, P, Vassena, C, Zebra, E, Picollo, M, P2007, 'Effectiveness of lotions based on essential oils from aromatic plants against permethrin resistant pediculus humanus capitis', Archives of Dermatological Research, Vol. 299, Issue. 8, pp.389-392.

7. Heukelbach, J, Speare, R \& Canyon, D 2006, 'Natural products and their application to the control of bhead lice: An evidence-based review', Chemistry of natural products: recent trends and developments, India.

8. Mehlhorn, H, Abdel-Ghaffar, F, Al-Rashidi KAS, Schmidt, J \& Semmler, M 2011, 'Ovicidal effects of a neem seed extract preparation on eggs of body and head lice', Parasitology Research, vol. 109, no. 5, pp. 1299-1302.

9. Toloza, AC, Lucia, A, Zebra, E, Masuh, H \& Picollo,MI 2009, 'Eucalyptus essential oil toxicity against permethrin-resistant Pediculus himanus capitis (Phthirapera: Pediculidae)', Parasitol Res, vol. 106, no. 2, pp. 409-414.

10. Upadhyay, S, Ghosh, AK \& Singh, V 2011, 'Anti-lice activity of Abrus precatorius LINN (FAM-Fabacae) seeds oil', Egyption dermatology online journal, vol. 7, no. 2, pp. 1-6.

11. Veal, L 1996, 'The potential effectiveness of essential oils as a treatment for head lice, Pediculus humanus capitis', Complementary Theraoies in Nursing and Midwifery, vol. 2, no. 4, pp. 97-101.

12. Walton, SF, McKinnon, M, Pizzutto, S, Dougall, A, Williams, E \& Currie, BJ 2004, 'Acaricidal activity of Melaleuca alternifolia (tea tree) oil: in vitro sensitivity of sarcoptes scabiei var hominis to terpinene-4-ol', Arch. Dermatol., vol. 140, no. 5, pp. 563-566.

13. Waghmare, JS and Dhumal, TD 2014, 'Mechanism of action of essential oil on Pediculus humanus capitis', Research journal of pharmaceutical, biological and chemical science, vol. 5, no. 4, pp. 894-901.

14. Yang, YC, Lee, HS, Clark, JM \& Ahn, YJ 2004, 'Insecticidal activity of plant essential oils against pediculus humanus (Anoplura: Pediculidae)', Journal of medical entomology, vol. 41, no. 4, pp. 699-704. 